\title{
Avaliação histológica dos testículos de ovinos da raça Santa Inês nascidos em diferentes estações do ano
}

\author{
Histological evaluation of Santa Ines sheep testicles born in different seasons
}

\author{
Concepta McManus ${ }^{\mathrm{I}}$ Luiz Claudio Bastos Sasaki ${ }^{\mathrm{I}}$ Helder Louvandini ${ }^{\mathrm{I}}$ Laila Talarico Dias ${ }^{\mathrm{II}}$ \\ Rodrigo de Almeida Teixeira' ${ }^{\mathrm{III}}$ Jordan Menezes Alves ${ }^{\mathrm{I}}$ Carolina Madeira Lucci ${ }^{\mathrm{I}}$ \\ Pablo Henrique Pereira Marsiaj ${ }^{\mathrm{I}}$ Luci Sayori Murata ${ }^{{ }^{*}}$
}

\section{RESUMO}

Foram analisados quatro grupos de ovinos machos da raça Santa Inês nascidos em quatro estações do ano, no Distrito Federal, a fim de observar as idades e o peso corporal em que estes atingiram a puberdade. A partir dos cortes histológicos dos testículos, foram analisados parâmetros celulares e mensurações dos túbulos seminíferos. O efeito da data de nascimento sobre os parâmetros avaliados foi significativo $(P<0,01)$, indicando que a estação do ano influenciou as características histológicas dos testículos dos cordeiros Santa Inês. Os animais nascidos no período da seca apresentaram maior precocidade à puberdade, porém pior perfil histológico dos testículos. O final da época de águas apresentou-se como a melhor estação para nascimentos de ovinos na região Central do Brasil, com características histológicas testiculares mais desejáveis na puberdade desses animais.

Palavras-chave: morfologia testicular, ovinocultura, puberdade, reprodução, sazonalidade.

\section{ABSTRACT}

Four groups of Santa Inês male sheep born in four seasons in the Distrito Federal were analyzed to evaluate the age and body weight at puberty, at which point were castrated. Histological measurements were carried out on the testicles to evaluate cellular parameters and size measurements of the seminiferous tubules. The effect of the group on cellular parameters was significant $(P<0.01)$. Animals born in the dry season were more precocious than the others, but showed the worst histological profile of the testis. The histological traits of the testis of the Santa Inês rams were influenced by the season.
The end of the rainy season was shown to the best season for births of sheep in the Central region of Brazil, with histological testicular traits at puberty being superior to the other groups.

Key words: puberty, seasonality, sheep production, reproduction, testicular morphology.

\section{INTRODUÇÃO}

Os ovinos apresentam mecanismos anatômicos e fisiológicos que lhes conferem capacidade de adaptação em ambientes de temperaturas altas e baixa umidade do ar. Dessa forma, a região do Distrito Federal mostra-se favorável à criação desses animais dada às condições ambientais e climáticas. O clima do Centro-Oeste é propício e comparável ao de outras regiões em que a ovinocultura é desenvolvida (McMANUS et al., 2009), sendo este um dos principais motivos que tem levado ao crescimento dessa atividade nessa região.

No Brasil, existem poucos trabalhos que caracterizam a população ovina produtiva e reprodutivamente (MARTINS et al., 2004), sendo a maioria realizada na região Nordeste do país. Entretanto, com o aumento da procura e consequentemente da produção da carne ovina no Brasil Central, é de fundamental importância obter informações a respeito do perfil produtivo da população ovina nessa região.

'Faculdade de Agronomia e Medicina Veterinária, Universidade de Brasília (UnB), 70910-900, Brasília, DF, Brasil. E-mail: mluci@unb.br. *Autor para correspondência.

"Departamento de Zootecnia, Ciência Agrárias, Universidade Federal do Paraná (UFPR), Curitiba, PR, Brasil.

IIIUniversidade Estadual de Ponta Grossa. Avenida Carlos Cavalcanti, 4748, Bloco F, sala 06, Uvaranas, 84030-900, Ponta Grossa, PR, Brasil 
Em geral, os estudos realizados no Distrito Federal sobre essa espécie desconsideram as características reprodutivas dos machos. ALVES (2006) ressaltou a importância da caracterização do perfil reprodutivo dos machos, o que permitiria adequar o manejo nos rebanhos, saber o momento exato da separação de machos e fêmeas e otimizar o uso dos reprodutores dentro do rebanho e, com isso, tornar mais eficiente o melhoramento genético desses animais nos plantéis. Atualmente, existem poucas informações disponíveis a respeito do desempenho reprodutivo de carneiros criados na região Centro-Oeste. Sendo assim, o objetivo do presente trabalho foi estudar o efeito da sazonalidade sobre a idade e o peso corporal à puberdade em cordeiros machos da raça Santa Inês nascidos em diferentes épocas do ano, na região Centro-Oeste, e como estas relacionam-se com características histológicas dos testículos destes após orquiectomia.

\section{MATERIAL E MÉTODOS}

O trabalho foi realizado no Centro de Ovinos da Fazenda Água Limpa (FAL), Universidade de Brasília (UnB), localizada no Distrito Federal a $15^{\circ} 47^{\prime}$ de latitude sul e $47^{\circ} 56^{\prime}$ de longitude oeste, sendo o clima da região caracterizado por estações de águas (outubro a abril) e secas (maio a setembro).

Foram selecionados quatro grupos de machos da raça Santa Inês, totalizando 33 ovinos, nascidos em intervalos de três meses, com idade média para a entrada no experimento de 94,91 $( \pm 12,88)$ dias. Os cordeiros foram manejados em um único grupo junto com os demais animais da propriedade, criados em pastagem (Andropogon gayanus), com fornecimento à vontade de sal mineral. Na época seca, esses animais receberam suplementação com $300 \mathrm{~g} / \mathrm{animal} / \mathrm{dia}$ de concentrado.

O primeiro grupo foi formado em $01 / 11 / 2003$, por animais nascidos entre julho e agosto (inverno, $\mathrm{n}=9$ ); o segundo, em 31/01/2004, por animais nascidos entre outubro e novembro (primavera, $n=9$ ); o terceiro, em 13/05/2004, por cordeiros nascidos em fevereiro (verão, n=7); e o quarto grupo, em 01/08/2004, por cordeiros nascidos entre março e maio (outono, $\mathrm{n}=8$ ).

Para detecção da puberdade, foram realizadas coletas de sêmen dos animais, por meio do método de eletro-ejaculação. As primeiras coletas foram mensais até que os primeiros espermatozoides fossem identificados. Posteriormente, as coletas foram realizadas quinzenalmente a fim de determinar a idade à puberdade, tendo como parâmetros a taxa de mobilidade espermática total (acima de 10\%) e concentração de, no mínimo, 50x $10^{6}$ espermatozóides $\mathrm{ml}^{-1}$ (WHEATON \& GODFREY, 2003). Os animais que atingiam a puberdade segundo os critérios relacionados anteriormente foram submetidos a outra coleta de sêmen após 15 dias, quando então foram pesados e, em seguida, orquiectomizados. Ambos os testículos foram lavados em solução fisiológica $0,9 \%$, e três fragmentos de aproximadamente $1 \mathrm{~cm}^{3}$ foram escolhidos aleatoriamente, retirados e fixados em paraformaldeído $8 \%$. Após a fixação, o tecido foi desidratado em concentrações crescentes de etanol, diafanizado em xilol e embebido em parafina, para a formação de blocos. $\mathrm{O}$ material foi cortado a $3 \mu \mathrm{m}$ de espessura e corado com hematoxilina e eosina. De cada bloco, foram preparadas e analisadas três lâminas por blocos.

$\mathrm{Na}$ avaliação microscópica dos túbulos seminíferos, para análise e captura das imagens das lâminas produzidas, utilizou-se um microscópio AxioSkop (Zeiss) acoplado com câmera CCD digital colorida (Sony - DXC-107) e microcomputador com placa digital de captura Pixel View Play TV (320x240 pixels). De cada lâmina, foram avaliados cinco túbulos seminíferos, determinados ao acaso, nos quais foram observados o número de células de Sértoli, o número de células da linhagem espermatogênica, a presença de espermatozoides, o diâmetro e a circunferência do túbulo e do lúmen e a altura do epitélio seminífero. As medidas foram tomadas por meio do programa para análises morfométricas Image-Pro Plus ${ }^{\circledR}$ - 5.0 (2001) e são apresentadas nas figuras 1 e 2.

O delineamento experimental foi inteiramente casualizado, e os dados foram analisados por meio dos procedimentos GLM, PRINCOMP e CORR do SAS INSTITUTE (2004). O efeito de época de nascimento foi utilizado como efeito fixo na análise de variância, e a idade e o peso na puberdade (linear e quadrático) foram utilizados como covariáveis.

\section{RESULTADOS E DISCUSSÃO}

As médias de idade na puberdade foram as seguintes: grupo $1=162,55$; grupo $2=229,55$; grupo $3=181,71$ e grupo $=202,50$ dias. Os pesos dos ovinos na puberdade, nos grupos 1, 2, 3 e 4, foram 23,98, 24,99, 21,83 e 24,46kg, sem diferença significativa entre eles. Os animais mais precoces (grupo 1) foram os que nasceram na seca (julho e agosto) e que iniciaram o experimento na estação chuvosa, época em que houve aumento da quantidade e da qualidade de forragem. $\mathrm{O}$ fato de a estação do ano influenciar a idade à puberdade pode ser explicado pelas variações nutricionais observadas ao longo do ano no Brasil Central, uma vez que o fotoperíodo não é um fator importante, pois nessa 

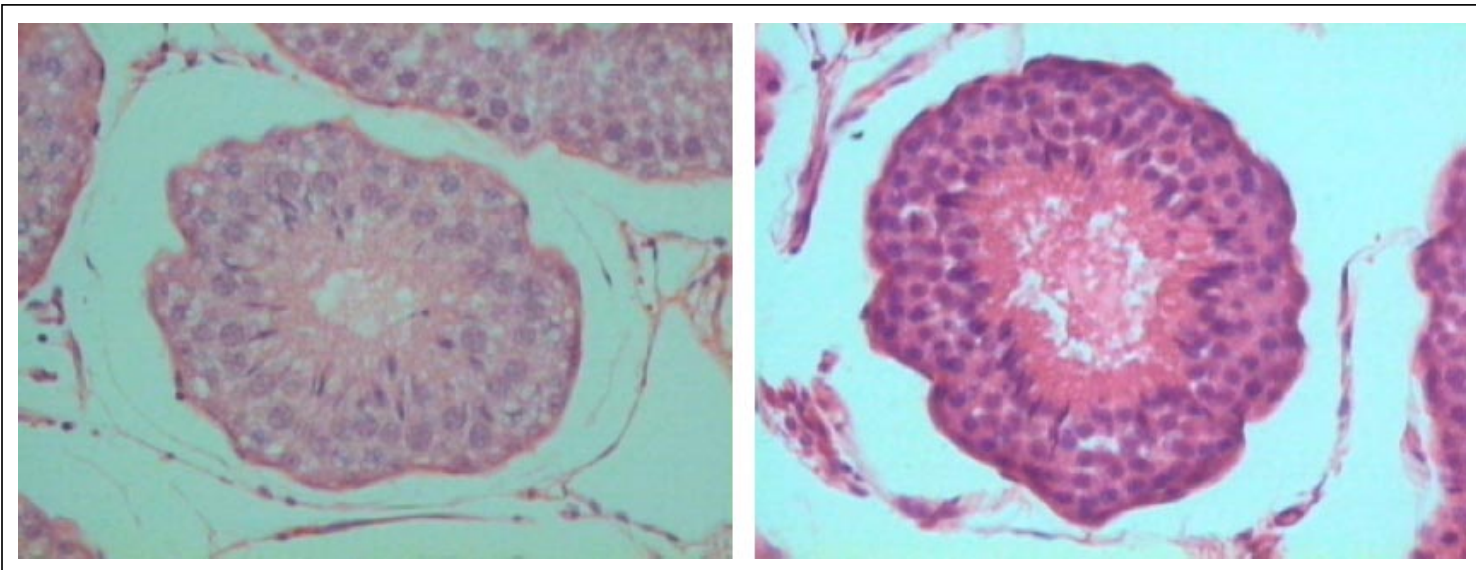

Figura 1 - A: Túbulo seminífero de corte histológico do testículo de um animal pertencente ao grupo 1 em lente de aumento 20x. B: Túbulo seminífero de corte histológico do testículo de um animal pertencente ao grupo 4 em lente de aumento $20 \mathrm{x}$.

região há pouca variação de luminosidade ao longo do ano. Segundo NUNES (2001), em zonas tropicais e subtropicais, a escassez de alimentos é provavelmente um dos principais fatores que limitam o desempenho reprodutivo. O nascimento na época seca pode favorecer a cria pela ausência de umidade excessiva, proporcionando ambiente favorável ao recém-nascido, pois nessa fase sua alimentação é totalmente

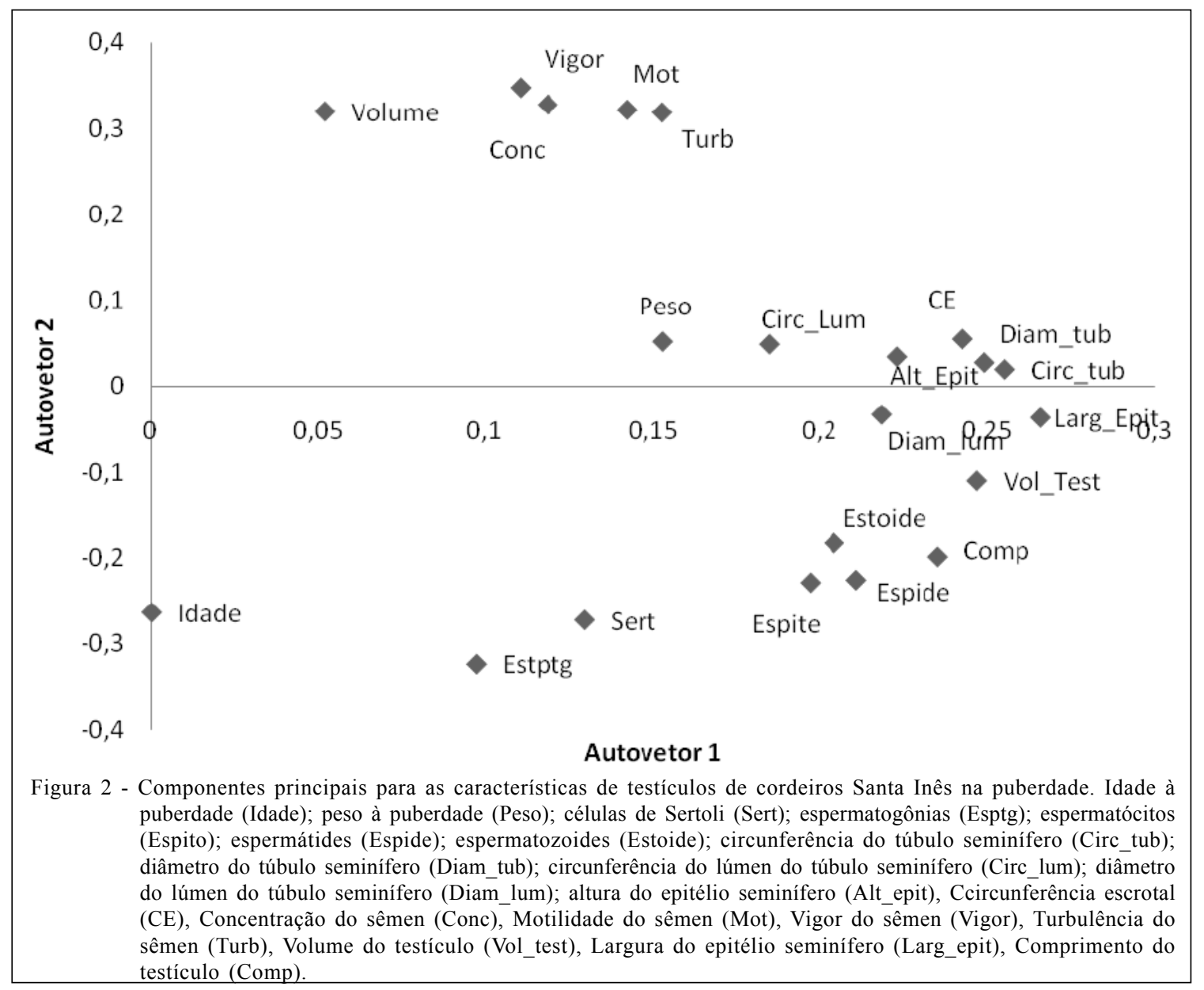

Ciência Rural, v.40, n.2, fev, 2010. 
dependente do leite materno, o que proporciona diminuição da incidência de doenças.

Resultado semelhante foi obtido por PAPACHRISTOFOROU et al. (2000), que observaram variação na idade à puberdade de ovelhas gregas de acordo com a estação de nascimento. No Brasil, MARTINS et al. (2004) relataram que as variações estacionais influenciaram a qualidade seminal e, consequentemente, o diagnóstico de fertilidade de ovinos adultos da raça Santa Inês na região do Distrito Federal.

A tabela 1 apresenta o resumo da análise de variância para a contagem celular e as mensurações dos túbulos seminíferos. Pode-se observar na tabela que o efeito de época de nascimento (grupo) influenciou significativamente todas as características avaliadas, exceto a altura do epitélio seminífero. Como os animais nasceram em diferentes épocas do ano, as variações na disponibilidade de alimento ocorridas no período influenciaram o desenvolvimento das gônadas, o que refletiu diretamente na estrutura histológica dos tecidos.

A contagem celular foi analisada e pode-se verificar que os efeitos de idade na puberdade foram significativos para espermatogônias (linear e quadrático), como também para o número de espermátides (linear). Porém, os efeitos de peso linear e quadrático não foram significativos para nenhuma das características histológicas estudadas. Segundo HAFEZ (1995), o fator determinante da puberdade está mais relacionado com o peso corporal do que com a idade ou raça dos animais.
No presente trabalho, os efeitos de idade e peso não foram identificados, provavelmente devido a diferenças existentes entre os animais dentro de cada grupo. Na tabela 2, estão apresentadas as médias da contagem das células de Sértoli e da linhagem espermatogênica nos túbulos seminíferos de animais nascidos nas diferentes estações do ano. Pode-se observar que o grupo de animais nascidos entre julho e agosto (seca) apresentou as menores contagens no número total de células, no túbulo seminífero. De acordo com CUNNINGHAM (1999), a população das células de Sértoli já está estabelecida antes da puberdade, quando perdem a habilidade de realizar mitoses. Apesar da suplementação alimentar recebida pelas matrizes e/ou borregos durante a estação da seca, observa-se que esta não foi suficiente para possibilitar melhor desenvolvimento histológico testicular em relação aos ovinos púberes na época das águas.

BRONGNIART et al. (1985) realizaram estudo com cortes histológicos de testículos de cordeiros que foram submetidos a restrições alimentares do nascimento à puberdade e observaram número reduzido de células de Sértoli em comparação com o grupo controle. Para carneiros adultos da raça Merino, HÖTZEL et al. (1998) relataram diminuição no número de células de Sértoli para o grupo de animais que tiveram dieta pobre em proteína em relação ao grupo de animais que receberam dieta com alto teor de proteína. Resultado semelhante foi observado por CARRIJO JUNIOR (2008), que observou menor número de células de Sértoli para os animais da raça Santa Inês que

Tabela 1 - Resumo da análise de variância para e contagem celular e mensurações dos túbulos seminíferos dos cortes histológicos dos testículos de cordeiros da raça Santa Inês na puberdade, no Distrito Federal.

\begin{tabular}{|c|c|c|c|c|c|}
\hline \multirow{2}{*}{ Célula } & \multirow[b]{2}{*}{ Grupo } & \multirow[b]{2}{*}{ Idade } & \multirow[b]{2}{*}{ Idade $^{2}$} & \multirow[b]{2}{*}{ Peso } & \multirow[b]{2}{*}{$\mathrm{Peso}^{2}$} \\
\hline & & & & & \\
\hline Sertoli & $* * *$ & ns & ns & ns & ns \\
\hline Esptg & $* * *$ & $*$ & $*$ & ns & ns \\
\hline Espcts & $* * *$ & ns & ns & ns & ns \\
\hline Espide & $* * *$ & $*$ & ns & ns & ns \\
\hline Esptzd & $* *$ & ns & ns & ns & ns \\
\hline Medida & -------- & -------- & os túbul & --------- & ----- \\
\hline Circ_tub $(\mu \mathrm{m})$ & $*$ & $*$ & $*$ & ns & ns \\
\hline Circ_lum $(\mu \mathrm{m})$ & $*$ & $*$ & $*$ & ns & ns \\
\hline Di_tub $(\mu \mathrm{m})$ & $*$ & $*$ & $*$ & ns & ns \\
\hline Di_lum $(\mu \mathrm{m})$ & $* *$ & ns & ns & ns & ns \\
\hline Alt_ep $(\mu \mathrm{m})$ & $\mathrm{ns}$ & $*$ & $\mathrm{~ns}$ & ns & ns \\
\hline
\end{tabular}

Sertoli: nº. de células de Sértoli; Esptg: nº . espermatogônia; Espcts: nº . espermatócitos; Espide: $n^{\circ}$. espermátide; Esptzd: $n^{\circ}$. espermatozoide; Circ_tub: circunferência do túbulo seminífero; Circ_lum: circunferência do lúmen do túbulo seminífero; Di tub: diâmetro do túbulo seminífero; Di lum: diâmetro do lúmen do túbulo seminífero; Alt ep: altura do epitélio seminífero, Idade = idade à puberdade linear; Idade $=$ idade à puberdade quadrático; $P$ eso $=$ peso à puberdade linear; $\mathrm{Peso}^{2}=$ peso à puberdade quadrático; ns: não significativo; $*$ P $<0,05$; $* * \mathrm{P}<0,01 ; * * * \mathrm{P}<0,001$. 
Tabela 2 - Médias dos valores obtidos para contagem celular e mensurações dos túbulos seminíferos dos cortes histológicos dos testículos de cordeiros da raça Santa Inês na puberdade, no Distrito Federal.

\begin{tabular}{|c|c|c|c|c|}
\hline \multirow[t]{2}{*}{ Célula } & \multicolumn{4}{|c|}{ 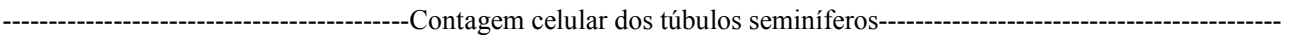 } \\
\hline & Julho-agosto (Grupo 1) & Outubro-novembro (Grupo 2) & Janeiro-fevereiro (Grupo 3) & Abril-maio (Grupo 4) \\
\hline Sertoli & $6,42^{\mathrm{a}}$ & $9,22^{\text {bc }}$ & $8,58^{\mathrm{b}}$ & $10,44^{\mathrm{c}}$ \\
\hline Esptg & $14,40^{\mathrm{a}}$ & $19,54^{\mathrm{b}}$ & $20,14^{\mathrm{b}}$ & $25,04^{\mathrm{c}}$ \\
\hline Espcts & $24,90^{\mathrm{a}}$ & $29,57^{\mathrm{b}}$ & $24,41^{\mathrm{a}}$ & $45,22^{\mathrm{c}}$ \\
\hline Espide & $37,06^{\mathrm{c}}$ & $54,07^{\mathrm{b}}$ & $42,70^{\mathrm{c}}$ & $71,08^{\mathrm{d}}$ \\
\hline Esptzd & $6,69^{\mathrm{a}}$ & $14,05^{\mathrm{b}}$ & $6,28^{\mathrm{a}}$ & $17,90^{\mathrm{c}}$ \\
\hline Medida & \multicolumn{4}{|c|}{ Mensurações dos túbulos seminíferos } \\
\hline Circ_tub $(\mu \mathrm{m})$ & $576,95^{\mathrm{a}}$ & $581,84^{\mathrm{a}}$ & $519,37^{\mathrm{b}}$ & $615,68^{\mathrm{c}}$ \\
\hline Circ_lum $(\mu \mathrm{m})$ & $269,37^{\mathrm{a}}$ & $229,83^{\mathrm{b}}$ & $219,42^{b}$ & $292,28^{\mathrm{c}}$ \\
\hline Di_tub $(\mu \mathrm{m})$ & $158,61^{\mathrm{a}}$ & $158,38^{\mathrm{a}}$ & $139,65^{\mathrm{b}}$ & $167,51^{\mathrm{a}}$ \\
\hline Di_lum $(\mu \mathrm{m})$ & $62,62^{\mathrm{a}}$ & $59,57^{\mathrm{ab}}$ & $55,18^{\mathrm{b}}$ & $75,34^{\mathrm{c}}$ \\
\hline Alt_ep $(\mu \mathrm{m})$ & $46,67^{\mathrm{a}}$ & $48,26^{\mathrm{a}}$ & $43,21^{\mathrm{a}}$ & $47,12^{\mathrm{a}}$ \\
\hline
\end{tabular}

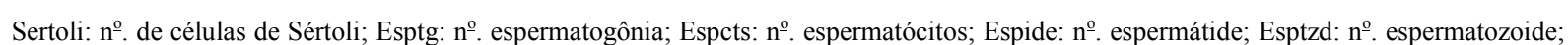
Circ_tub: circunferência do túbulo seminífero; Circ_lum: circunferência do lúmen do túbulo seminífero; Di tub: diâmetro do túbulo seminífero; Di_lum: diâmetro do lúmen do túbulo seminífero; Alt_ep: altura do epitélio seminífero. Médias seguidas por letras diferentes na mesma coluna são significativamente diferentes entre si pelo teste $\overline{\text { de }}$ Tukey $(\mathrm{P}<0,05)$.

receberam ração com baixo teor de proteína e que não foram vermifugados.

A quantidade de células da linhagem espermatogênica apresentou proporcionalidade em relação ao número de células de Sértoli. Os animais nascidos entre julho e agosto foram os que apresentaram a menor quantidade dessas células (Tabela 2), sendo o fator nutricional na época seca o provável responsável pelos resultados obtidos, conforme já discutido anteriormente. HÖETZEL et al. (1998) e BIELLI et al. $(1999,2000)$ relataram que animais alimentados com concentrado apresentaram aumento no número total de células da linhagem espermatogênica, portanto o fornecimento de ração balanceada pode influenciar positivamente a espermatogênese. Entretanto, esses resultados discordam dos resultados obtidos por CARRIJO JÚNIOR (2008), que observou maior número de espermatogônias nos animais alimentados com dieta com baixo teor de proteína. Segundo o autor, esse aumento no número de espermatogônias pode ter sido gerado por um desequilíbrio no processo de espermatogênese.

As maiores contagens para linhagem espermatogênica foram obtidas nos animais nascidos no período chuvoso, em abril/maio (Tabela 2). Verificouse que os menores valores médios (Tabela 2) obtidos para todas as características avaliadas nos túbulos seminíferos dos testículos de cordeiros Santa Inês foram do grupo 3, animais que nasceram na época das chuvas (janeiro e fevereiro), sendo as maiores médias as dos animais pertencentes ao grupo 4 (Figura 1), nascidos no mês de abril e maio, com exceção da altura do epitélio. Novamente, o efeito da época de nascimento foi significativo $(\mathrm{P}<0,05)$ para todas as características mensuradas, com exceção da altura do epitélio, em que o efeito não foi significativo (Tabela 1).

$\mathrm{O}$ efeito linear de idade foi significativo $(\mathrm{P}<0,05)$ para as características analisadas, exceto para diâmetro do lúmen do túbulo seminífero (Dilum), em que não se observou efeito linear e quadrático da idade; para altura do epitélio seminífero, o efeito quadrático de idade não foi significativo. Os efeitos linear e quadrático de peso não foram significativos para nenhuma das características estudadas, talvez pela pequena diferença de peso entre os animais desse conjunto de dados (Tabela 1).

Um dos principais fatores que podem ter influenciado a morfologia testicular foi a nutrição dos animais, uma vez que, entre as duas épocas (seca e águas), houve grande variação na disponibilidade de forragem fornecida aos cordeiros. Resultado semelhante foi apresentado por REGE et al. (2000), os quais observaram que o efeito da época do ano influenciou significativamente a circunferência escrotal, motilidade, concentração e quantidade de defeitos espermáticos e atribuíram as diferenças observadas à nutrição dos cordeiros. 
As estimativas de correlação entre idade na puberdade e os parâmetros histológicos avaliados foram positivas e variaram de baixas a moderadas (Tabela 3), porém foram negativas quando correlacionadas com as características morfológicas dos túbulos seminíferos, indicando que animais com maiores idades apresentaram menores medidas. SOUZA et al. (2003) relataram que animais mais precoces tendem a apresentar maior circunferência escrotal e concentração espermática em idades mais avançadas. As correlações estimadas entre o peso e as células dos testículos e a morfometria dos túbulos seminíferos variaram de zero a 0,31 (Tabela 3 ). Porém, outros autores encontraram altas correlações entre o peso e os parâmetros externos dos testículos (ALVES, 2006).

Dentre os parâmetros histológicos, as correlações foram positivas e variaram de moderada a alta, indicando que, quanto maior o volume tubular, maior a quantidade de células. Quanto aos caracteres morfológicos dos túbulos seminíferos, as correlações obtidas foram altas e positivas, concordando com os resultados obtidos por CARRIJO JÚNIOR (2008). As estimativas de correlações estimadas entre os parâmetros histológicos e as características morfológicas dos túbulos seminíferos foram positivas e variaram de baixa $(0,10)$ entre o número de célula de Sértoli e a circunferência do lúmen do túbulo seminífero a alta $(0,71)$ entre espermatócitos e diâmetro do lúmen do túbulo seminífero.

A análise de componentes principais foi realizada para auxiliar na interpretação das relações existentes entre as variáveis estudadas, e os resultados estão apresentados na figura 2. Observando-se o primeiro autovetor (eixo x) na figura 2, é possível notar que animais mais pesados apresentam testículos maiores e, consequentemente, melhores valores dos parâmetros histológicos, com maior número de células da linhagem espermatogênica e túbulos seminíferos de maiores tamanhos. A idade na puberdade não influenciou significativamente as características estudadas, já o peso corporal pode ser considerado como um indicador eficiente dessas características. Além disso, quanto maior o valor da circunferência dos túbulos seminíferos, maior é o número total de células presentes nos túbulos.

No segundo autovetor (eixo y), verifica-se que os animais mais precoces (com menores idades à puberdade) apresentaram baixa quantidade de células dos túbulos seminíferos, e o peso corporal na puberdade teve pouca influência sobre essa característica. Para esse subgrupo, houve pouca variação das mensurações dos túbulos seminíferos, quando comparados aos demais grupos. Os dois autovetores relacionados explicaram $68 \%$ das variações entre as características avaliadas.

\section{CONCLUSÃO}

Os ovinos com nascimentos ocorridos no final da época de águas (abril-maio) apresentaram melhores características histológicas testiculares na puberdade, indicando ser esta a melhor estação para nascimentos de ovinos com finalidade reprodutiva na região Central do Brasil.

Tabela 3 - Estimativas de correlações entre a idade e peso à puberdade e as mensurações histológicas e morfológicas dos túbulos seminíferos em cordeiros Santa Inês.

\begin{tabular}{|c|c|c|c|c|c|c|c|c|c|c|c|}
\hline & Idade & Peso & Sertoli & Esptg & Espcts & Espide & Esptzd & Circ_tub & Circ_lum & Di_tub & Di_lum \\
\hline Peso & 0,25 & & & & & & & & & & \\
\hline Sertoli & 0,19 & 0,00 & & & & & & & & & \\
\hline Esptg & 0,24 & 0,01 & 0,79 & & & & & & & & \\
\hline Espcts & 0,12 & 0,16 & 0,65 & 0,73 & & & & & & & \\
\hline Espide & 0,16 & 0,20 & 0,78 & 0,68 & 0,85 & & & & & & \\
\hline Esptzd & 0,19 & 0,31 & 0,52 & 0,36 & 0,65 & 0,67 & & & & & \\
\hline Circ_tub & $-0,16$ & 0,28 & 0,39 & 0,30 & 0,67 & 0,65 & 0,63 & & & & \\
\hline Circ_lum & $-0,15$ & 0,09 & 0,10 & 0,25 & 0,58 & 0,38 & 0,40 & 0,76 & & & \\
\hline Di_tub & $-0,18$ & 0,25 & 0,36 & 0,31 & 0,69 & 0,66 & 0,56 & 0,97 & 0,78 & & \\
\hline Di_lum & $-0,12$ & 0,20 & 0,36 & 0,42 & 0,71 & 0,58 & 0,51 & 0,83 & 0,88 & 0,84 & \\
\hline Alt_ep & $-0,20$ & 0,21 & 0,42 & 0,23 & 0,55 & 0,62 & 0,53 & 0,90 & 0,50 & 0,88 & 0,56 \\
\hline
\end{tabular}

Idade $=$ idade à puberdade; Peso $=$ peso à puberdade; Sertoli: $\mathrm{n}^{\mathrm{o}}$. de células de Sértoli; Esptg: $\mathrm{n}^{\circ}$.espermatogônia; Espcts: $\mathrm{n}^{\mathrm{o}}$. espermatócitos; Espide: $\mathrm{n}^{\circ}$. espermátide; Esptzd: nº. espermatozoide; Circ tub: circunferência do túbulo seminífero; Circ lum: circunferência do lúmen do túbulo seminífero; Di_tub: diâmetro do túbulo seminífero; Di_lum: diâmetro do lúmen do túbulo seminífero; Alt_ep: altura do epitélio seminífero. 


\section{AGRADECIMENTOS}

Os autores agradecem à Finatec, ao CNPq (INCTIGS) e à Fundação de Apoio à Pesquisa do Distrito Federal (FAP-DF), pelo financiamento e pelas bolsas.

\section{APROVAÇÃo DO COMITÊ DE ÉTICA}

A pesquisa foi aprovada pelo Comitê de Ética no Uso Animal (CEUA) da Universidade de Brasília (processo no 33/2009).

\section{REFERÊNCIAS}

ALVES, J.M. et al. Estação de nascimento e puberdade em cordeiros Santa Inês. Revista da Sociedade Brasileira de Zootecnia, Viçosa, v.35, n.3, p.958-966, 2006. Disponível em: $<$ http://www.scielo.br/scielo.php?script=sci_arttext\&pid=S1516$35982006000400004 \& \operatorname{lng}=\mathrm{pt} \& \mathrm{nrm}=\mathrm{iso} \& \mathrm{t} \operatorname{lng}=\mathrm{pt}>$. Acesso em: 06 out. 2009. doi: http://dx.doi.org/10.1590/S151635982006000400004 .

BIELLI, A. et al. Influence of grazing management on the seasonal change in testicular morphology in Corriedale rams. Animal Reproduction Science, v.56, p.93-105, 1999. Disponível em: <http://www.sciencedirect.com/ science?_ob=ArticleURL\&_udi=B6T43-3X10TB9$2 \&$ user $=6 \overline{8} 7355 \&$ rdoc $=1 \& \mathrm{fmt}=\&$ orig $=$ search $\&$ sort $=\mathrm{d} \&$ do canchor $=\&$ view $=$ c\&_acct $=\mathrm{C} 000037918 \&$ \&ersion $=\overline{1} \&$ urlVersion $=0 \&$ userid $=687355 \& \mathrm{md} 5=755 \mathrm{~d} 8 \mathrm{~d} 17380 \mathrm{cadb} 4 \mathrm{~b} 89 \mathrm{abb} 7 \mathrm{a} 3158 \mathrm{cb} 82>$. Acesso em: 03 out. 2009. doi: http://dx.doi.org/10.1016/S03784320(99)00027-5.

BIELLI, A. et al. Influence of pre and post-pubertal grazing regimes on adult testicular morphology in extensively reared Corriedale rams. Animal Reproduction Science, v.58, p.7386, 2000. Disponível em: <http://www.sciencedirect.com/ science?_ob=ArticleURL\&_udi=B6T43-3 YNY 75 T$7 \&$ \&user $=687355 \&$ _rdoc $=1 \&$ fmt $=$ \&_orig $=$ search $\&$ _sort $=\mathrm{d}$ $\&$ _doc anchor $=\&$ vi e w $=$ c \&_a c c t $=$ C 000003791 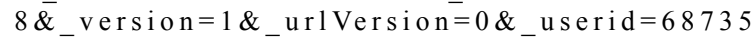 $5 \& \overline{m d} 5=749 \mathrm{e} 7051703 \mathrm{c} 2249 \mathrm{a} 7456 \mathrm{ea} 5 \mathrm{e} 512 \mathrm{e} 304>$. Acesso em: 03 out. 2009. doi: http://dx.doi.org/10.1016/S03784320(99)00076-7.

BRONGNIART, I. et al. Testis parameters, LH and testosterone secretion in underfed lambs. In: INTERNATIONAL CONGRESS OF ANDROLOGY, 3, 1985, Boston, Massachusetts. Journal of Andrology, supl.6, p.64, 1985.

CARRIJO JUNIOR, O. et al. Morphological evaluation of the testicles of young Santa Inês rams submitted to different regimes of protein supplementation and drenching. Ciência Animal Brasileira (UFG), v.9, p.433-441, 2008. Disponivel em: $<$ http://www.revistas.ufg.br/index.php/vet/article/viewFile/1091/ 3721>. Acesso em: 06 out.2009.

CUNNINGHAM, J.G. Tratado de fisiologia veterinária. 2.ed. Rio de Janeiro: Guanabara Koogan, 1999. 525p.

HAFEZ, E.S.E. Reprodução animal. 6.ed. São Paulo: Manole, 1995. 582p.

HÖETZEL, M.J. et al. Morphometric and endocrine analyses of the effects of nutrition on the testis of mature Merino rams. Journal of Reproduction and Fertility, v.113, p.217-230, 1998. Disponível em: <http://www.reproduction-online.org/cgi/ reprint/113/2/217>. Acesso em: 20 set. 2009.
MARTINS, R.D. et al. Uso do Ultra-som na predição de características de carcaça em carneiros Santa Inês submetidos à diferentes regimes de suplementação protéica e tratamentos anti helmínticos. ARS Veterinária, Jaboticabal, v.20, n.1, p.91-99, 2004.

McMANUS, C. et al. Heat tolerance in Brazilian sheep: physiological and blood parameters. Tropical Animal Health and Production, v.9, p.1, 2009. Disponível em: $<$ http:// www.springerlink.com/content/vu6554686713288j>. Acesso em: 20 set.2009. doi:http://dx.doi.org/10.1007/s11250-0089162-1.

NUNES, J.F. et al. Inseminação artificial em caprinos. In: GONÇALVES, P.B.D. et al. Biotécnicas aplicadas à reprodução animal. São Paulo: Varela Editora, 2002. Cap.7, p.111-125.

PAPACHRISTOFORO, C. et al. Seasonal effects on puberty and reproductive characteristics of female Chios sheep and Damascus goats born in autumn or in February. Small Ruminant Research, v.38, n.1, p.9-15, 2000. Disponível em: <http://www.sciencedirect.com/ science?_ob=ArticleURL\&_udi=B6TC5-40TY2HV$2 \&$ user $=687355 \&$ rdoc $=1 \&$ fmt $=\&$ orig $=$ search $\&$ sort $=\mathrm{d} \&$ 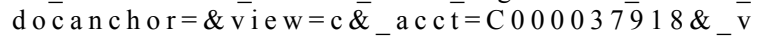 e rsion $=1 \&$ \& r l Version $=0 \&$ _userid $=687 \overline{3} 5$ $5 \& \mathrm{md} 5=18 \mathrm{f} 65 \mathrm{a} 4096 \mathrm{a} 7 \mathrm{c} 96 \mathrm{fcd} 4 \mathrm{da} 055 \mathrm{be} 855080>$. Acesso em: 20 set.2009. doi: http://dx.doi.org/10.1016/ S0921-4488(00)00143-7.

REGE, J.E.O. et al. Reproductive characteristics of Ethiopian highland sheep: II. Genetic parameters of semen characteristics and their relationships with testicular measurements in ram lambs. Small Ruminant Research, v.37, n.3, p. 173-187, 2000. Disponível em: <http://www.sciencedirect.com/ science? ob=ArticleURL\& udi=B6TC5-40J7B2D$1 \& \_$user $=687355 \& \_$rdoc $=1 \&$ fmt $=\&$ \& orig $=$ search\&_sort $=\mathrm{d} \& \_$docanchor $=$ $\&$ view $=$ c\&_searchStrI $d=1081397974 \&$ \&_rerunOrigin $=$ google\& acct $=\mathrm{C} 000037918 \&$ version $=\overline{1} \&$ urlVersion $=0 \&$ userid $=687355 \& \mathrm{md} 5=0 \mathrm{~b} 1308 \mathrm{f} 3 \mathrm{c} 5 \mathrm{ad} 268 \mathrm{c} 4 \mathrm{c} 14233 \mathrm{~b} 73 \mathrm{db} 12 \mathrm{f} 4>$. Acesso em: 05 out.2009. doi: http://dx.doi.org/10.1016/S09214488(00)00140-1.

SAS INSTITUTE. SAS/STAT 9.1 User's guide. Cary, North Carolina, 2004. 5136p. Disponível em: <http://www.books.google.com.br/ b o o k s ? i d = 2 o E Q y O I y C b U C \& p r i n ts ec $=$ frontcover $\& d q=s$ as + institute + us er $\%$ C 2 $\% \mathrm{~B} 4 \mathrm{~s}+\mathrm{g} \mathrm{uide}+1999 \& \mathrm{~s} \mathrm{our} \mathrm{c} \mathrm{e}=\mathrm{g} \mathrm{b} \mathrm{s}-\mathrm{s}$ imilarbooks_r\&cad $=2 \# \mathrm{v}=$ onepage $\& \mathrm{q}=\& \mathrm{f}=$ false $>$. Acesso em: 10 fev.2009.

SOUZA, C.E.A. et al. Estudo das interações entre o desenvolvimento gonadal, produção espermática, concentrações de testosterona e aspectos ligados à puberdade em carneiros Santa Inês ao longo do primeiro ano de vida. Revista Brasileira de Reprodução Animal, v.27, n.2, p.199-201, 2003.

WHEATON J.E.; GODFREY R.W. Plasma LH, FSH, testosterone, and age at puberty in ram lambs actively immunized against an inhibin a-subunit peptide. Theriogenology, v.60, p.933-941, 2003. Disponivel em: <http://www.sciencedirect.com/ science?_ob=ArticleURL\&_udi=B6TCM-487F $0 \mathrm{KJ}$ $3 \&$ \& user $=687355 \&$ rdoc $=1 \&$ _fmt $=\&$ \&orig $=$ search $\&$ sort $=$ d\& docanchor $=\&$ view $=$ c \& acct $=$ C $00003 \overline{7}$ $918 \&$ \&_version $=1 \&$ _ur 1 Version $=0 \&$ _us erid $=$ 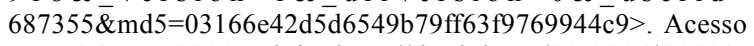 em: 06 out.2009. doi: http://dx.doi.org/10.1016/S0093691X(03)00104-3. 